Saša Moderc ${ }^{1}$

Maurizio Barbi ${ }^{2}$

Univerzitet u Beogradu

Filološki fakultet
УДК $821.163 .41 .03=131.1$

811.163.41'35:811.131.1'35

DOI https://doi.org/10.18485/zivjez.2017.37.1.2

Оригинални научни рад

\title{
ITALIJANSKI VULGARIZAM „CAZZO“ I NJEGOVO PREVOĐENJE NA SRPSKI JEZIK
}

Prevođenje vulgarizama s jednog jezika na drugi postavlja niz translatoloških problema. Vulgarizmi su često samo delimično obrađeni u dvojezičnim rečnicima, koji ne obuhvataju na celovit način kontekst i socio-kulturne faktore upotrebe vulgarizama. U prenošenju vulgarizama važni faktori su uticaj desemantizacije vulgarizama i njihove rekurzivnosti u tekstu, budući da oni utiču na stepen njihove prihvatljivosti. Proces desemantizacije vulgarizma "cazzo" i srpskog leksičkog ekvivalenta „kurac“ nije tekla paralelno u italijanskom i srpskom. Zato je prevodilac pozvan da iznađe vulgarizme s približnom socio-kulturnom prihvatljivošću. Istraživanje je vršeno na prevodima romana Federika Moče i fokusira se na frazeološke funkcije italijanskog vulgarizma „cazzo“ i na njene ekvivalente u prevodima na srpski.

Ključne reči: Federiko Moča, cazzo, kurac, prevođenje, vulgarizmi, srpski jezik, italijanski jezik, rekurzivnost, socio-lingvistička dimenzija.

Vulgarni izrazi, ili vulgarizmi, obuhvataju reči ili izraze koje se u datoj kulturi ili društvenoj zajednici smatraju neprimerenim, skaradnim ili uvredljivim za sagovornika. Sve ljudske zajednice poseduju u svom jeziku vulgarne reči i izraze ${ }^{3}$; njihova funkcija je, s jedne strane, da se pomoću njih izvede verbalni napad na druge učesnike u komunikaciji, odnosno da se na ekspresivan način izrazi širok spektar emotivnih reakcija. Tartamela (2006: 12) predlaže

$1 \quad$ smoderc@fil.bg.ac.rs

2 maurizio1973@yahoo.it

3 Kapuano (2007: 11) govori „sveopštoj raširenosti“ [diffusione ubiquitaria] psovki i uvredljivih izraza, ali napominje da one nisu samo odraz necivilizovanosti već da zavređuju da budu predmet ozbiljne analize. 
precizniju podelu vulgarizama: po ovom autoru oni imaju funkciju da govornik izrazi: (1) bes, (2) seksualnost, (3) odvratnost, (4) osećaj za humor, (5) prisnost; zatim, pomoću vulgarizama može se (6) privući pažnja, provocirati, pretiti, (7) marginalizovati sagovornik ili pak (8) uvrediti i diskvalifikovati. Vulgarizmi se u pogledu denotativnih svojstava najčešće nadovezuju na određene radnje ili pojmove koje zajednica govornika izbegava da pomene na direktan način. Vulgarizmi zadiru, u većoj ili manjoj meri - u zavisnosti od njihove denotativne dimenzije - $u$ antropološko polje zabrane i tabua. Treba razlikovati vulgarne izraze koji se odnose na sferu religije: oni se mogu objediniti pod zajedničkim terminom „bogohuljenje“, ili „blasfemija“, i neće biti predmet ovog rada; na ovom mestu možemo da podsetimo da Tartamela (2006: 15-16) smatra da nije svako pominjanje imena božijeg bogohulno samo po sebi. Ovaj autor razlikuje profanu upotrebu određenih reči i imena vezanih za sferu religije, kojima se ne vređaju verska osećanja: njihova funkcija je isključivo ekspresivna (takvi su, na primer, uzvici „Isuse“ ili „gospode Bože"). Blasfemija, s druge strane, predstavlja napad na božanstvo, na simbole ili na svetitelje neke vere. Drugi izrazi odnose se na uvredljivo, neprikladno i neprihvatljivo obraćanje sagovorniku; upotrebom vulgarnih reči i izraza ovaj se nipodaštava i ponižava. Radi postizanja takvog efekta u komunikaciji u nekim kulturama, među koje spadaju i naša i italijanska, pominju se delovi tela (i za njih vezane radnje), koji se u tradiciji date sredine smatraju nečistim (takav je slučaj s polnim organima i s analnom regijom u velikim monoteističkim religijama).

Vulgarizmi predstavljaju poseban translatološki problem zbog činjenice da oni u jeziku proizvode snažan emotivni i psihološki naboj i na jezgrovit i efektan način izražavaju stavove, reakcije ili osećanja govornika, odnosno - u slučaju ovog rada - likova književnih dela. Problemi u prevođenju vulgarizama nastaju delom zbog srpsko-italijanskih dvojezičnih rečnika, koji bi trebalo da budu neutralan i pouzdan oslonac u prevodilačkom radu; u njima je, međutim, neretko primenjena autocenzura te su vulgarizmi u dvojezičnim rečnicima često prikazani na eufemističan i ublažen način. Na taj način se prikriva ne samo njihova ekspresivnost već i funkcija koja 
im je namenjena u komunikaciji (i u književnom tekstu). Zbog toga korisnik rečnika, naročito ukoliko ne poznaje dovoljno dobro strani jezik, može steći krivu predstavu o semantici nekog vulgarnog izraza, a ukoliko rečnik nije opremljen odgovarajućim brojem primera, korisnik može da izvede i neprecizne zaključke o značenju i pragmatičkoj dimenziji datog vulgarnog izraza. Upravo je takav slučaj s italijanskim vulgarnim izrazom „cazzo“ (sr. „kurac"), koji je u italijansko-srpskom rečniku Ivana Klajna (str. 116) definisan samo kao (vulg.) „muški ud“, dok se za frazeološke primere upućuje na eufemizam „cavolo“ („,kupus“: isto na str. 116), koji se može upotrebiti umesto vulgarne reči „cazzo“. U italijansko-hrvatskom rečniku Deanović-Jernej leksikografska obrada ove reči je još više redukovana: ona je određena kao vulgarizam iz oblasti anatomije i definisana je, takođe, samo kao „muški ud“ (str. 166). Međutim, hrvatsko-italijanski rečnik propušta da obavesti o vezi između vulgarizma „cazzo“ i eufemističke upotrebe reči „cavolo“ (isto na str. 166). I dok srpski i hrvatski korisnici ovih rečnika bez teškoća razumeju koji je pravi leksički ekvivalent ove italijanske reči, za Italijana koji koristi ove rečnike takvo zaključivanje ne može biti spontano. Autori pomenutih dvojezičnih rečnika postupili su na način koji se sa socio-kulturnog aspekta može smatrati očekivanim. Naime, za razliku od srpskog i hrvatskog jezika, u italijanskom je reč „cazzo“ prošla proces desemantizacije, naročito kada je u pitanju njena upotreba kao samostalnog uzvika ili u frazeološkim konstrukcijama. Zbog raširene upotrebe ove reči u govornom jeziku i zbog smanjene osetljivosti na njeno osnovno, vulgarno značenje, ona se ne doživljava više kao posebno neprihvatljiv element izražavanja; ista konstatacija važi i za reči koje su od nje izvedene (cazzeggio, cazzeggiare, cazzone, cazzata itd.). Ne može se tvrditi da je u poslednjih pedesetak godina, kada je upotreba reči „cazzo“ postala vidljivija, došlo do naročitog opadanja moralnih normi i društvene pristojnosti u Italiji. Smatramo da su u pomenutom periodu, zahvaljujući sve većem prisustvu elemenata spontanog govora u medijima, u književnosti i, kasnije, na Internetu, prisustvo i upotreba vulgarizama postali samo vidljiviji, a da su oni i ranije bili rasprostranjeni u jeziku, ali nisu mogli da dopru do malobrojnih medija koji su bili na raspolaganju do pedese- 
tih godina XX veka. S druge strane, suviše su malobrojni uzorci tadašnjeg govornog jezika i oni ne mogu da se kvalitativno i kvantitativno uporede s obiljem spontanog jezičkog materijala koji nam je danas dostupan, kako u uređenim jezičkim korpusima, tako i na Internetu. Slično kao u italijanskom, kada je reč o procesu desemantizacije frekventnih vulgarizama, u srpskom jeziku danas ne izaziva naročitu reakciju izraz ,jebote“, pisan sastavljeno ili rastavljeno (ili u obliku skraćenice „jbt") ${ }^{4}$, odnosno ,jebiga“ (sastavljeno pisanje svedoči u prvom redu o njegovom statusu uzvika). Procesu desemantizacije ovog izraza doprineli su, najverovatnije, rasprostranjenost glagola „jebati“ (koji je zabeležen još u prvom Vukovom rečniku ${ }^{5}$ ) i njegov frazeološki potencijal, koji se realizuje u brojnim vulgarnim izrazima, samo formalno fokusiranim na polni čin ${ }^{6}$ a suštinski usmerenim na izražavanje širokog spektra negativnih stavova, poput odbacivanja, prezira, ljutnje itd.; pomoću njih se, takođe, iskazuju i pozitivni stavovi, zavisno od govorne situacije u kojoj je neki izraz upotrebljen.

Zbog činjenice da dvojezični rečnici nude samo uopšteno značenje nekog vulgarizma, prevodilac mora da za tekst svog prevoda iznađe izraze koji će u drugom jeziku imati što veću semantičku i pragmatičku sličnost s datim izrazom. Prevodilac mora da primi s kritičkom rezervom nekontekstualizovane sugestije rečnika - kada

$4 \quad$ Up. grafite u Novom Beogradu: NBG(D) JBT, „Novi Beograd jebote“, u kojima predmetni izraz treba - pretpostavljamo - da označi nametanje - za autore grafita neupitnog prvenstva Novog Beograda u odnosu na druge krajeve Beograda.

5 Glagol „jebati“ nije zabeležen ni u jednotomnom rečniku Matice srpske (izdanja 2007. i 2011), ni u šestotomnom izdanju Matičinog rečnika (1967-1976), kao ni u Rečniku srpskohrvatskog književnog i narodnog jezika SANU.

6 Zanimljiv je način na koji se Nikola Savić u svom romanu „Vita migliore“ („Bolji život": roman je izvorno napisan na italijanskom i naknadno je preveden na srpski) poigrao srpskim i italijanskim jezikom, preuzevši izraz iz maternjeg jezika ,jebali smo im kevu“ i doslovno ga prenevši u originalni italijanski tekst. Na taj način autor je ponudio italijanskom čitaocu besmislen iskaz (vulg. ,...gli abbiamo scopato la madre...") koja se u tom jeziku može tumačiti isključivo doslovno, kao polni čin. Možda su prevodioci na ovom mestu mogli da sačuvaju Savićevu interlingvističku pošalicu i nedoumicu za čitaoca tako što bi u srpskom tekstu ponudili doslovan prevod nekog ekvivalentnog italijanskog vulgarizma čiji je fokus nasilni obračun sa suparnicima, npr. „Gli abbiamo fatto un culo così (doslovno „Napravili smo im ovoliko dupe“, žargonski vulgarni izraz koji znači isto što i pomenuti srpski, „pretukli smo ih“). 
one postoje - i da iznađe ono rešenje koje najbolje odgovara komunikativnim intencijama datog mesta u književnom delu.

Socio-kulturna razlika u percepciji jednog i drugog vulgarizma („cazzo“ i „kurac") kod izvornih govornika jeste povod da analiziramo kako je italijanska reč „cazzo“ upotrebljena u romanima popularnog pisca Federika Moče i kako je ona transponovana u prevodima na srpski jezik. Oslanjamo se na ovog autora jer on u svojoj prozi nastoji da reprodukuje spontani govor mladih Italijana, čiji jezik obiluje žargonskim izrazima, kolokvijalizmima i vulgarizmima. Jezik ovog pisca XXI veka razlikuje se od jezika starijih italijanskih pisaca, koji su bili umereniji u prenošenju leksike i modela govornog jezika u književnost. Ukoliko bi raniji autori u svojim dijalozima oponašali govorni registar, vulgarne izraze bi izostavljali iz tekstova, ili bi ih cenzurisali u vidu skraćenica. Italijanski pisci pedesetih, šezdesetih i sedamdesetih godina su nastojali da svoj jezički izraz zadrže unutar granica konvencionalne „pristojnosti“ $i$,prihvatljivosti“, ostajući u okvirima tada dominantnih jezičkih i kulturnih modela. Kasnije, naročito od devedesetih godina, upotreba vulgarizama u književnosti raširila se među mnogim autorima. Ilustrovaćemo našu tvrdnju podacima koji se odnose na nekoliko italijanskih pisaca; naš izbor autora je proizvoljan i dobijeni podaci imaju samo indikativnu vrednost. Kod prvih posleratnih autora ${ }^{7}$ nismo zabeležili vulgarizam "cazzo“; isti rezultat smo dobili i kod predstavnika naredne generacije ${ }^{8}$. Neku vrstu prekretnice u upotrebi vulgarizama u književnosti predstavlja roman „Svinje s krilima“ (Radiče-Ravera), koji je objavljen 1976. godine i koji među prvima usvaja jezičke modele govora mladih. Pjer Vitorio Tondeli (1955-1991) je takođe upotrebljavao vulgarizme u svojim delima, naročito zbog toga što je svoje romane često ambijentirao u milje društvenih marginalaca.

$7 \quad$ Pretražili smo elektronska izdanja Kalvinovih dela (ukupno 15), Pazolinija (7), Vitorinija (4) i Pavezea (11). Kod Pazolinija, u Iskusnim momcima, vulgarizam „cazzo“ javlja se samo u skraćenom obliku („c."), mada su drugi vulgarni izrazi i reči napisani u integralnom obliku (ova konstatacija važi za roman „Ragazzi di vita“ - „Iskusni momci“). Ista skraćenica („,c.) javlja se kod Brankatija („Il bell'Antonio“ - „Lepi Antonio“), ali se odnosi na vulgarnu reč „coglione“. U prevodu na hrvatskosrpski ponuđena je ekvivalentna skraćenica „m.“, od „mudo“. Dino Bucati (5 dela), Karlo Kasola (14), Leonardo Šaša (16). 
U romanu „Svinje s krilima“ vulgarizam „cazzo“ javlja se 85 puta, dok se ista reč javlja ukupno 204 puta u šest Tondelijevih dela koja smo pretražili. Među savremenim autorima mogu se razlikovati oni koji su prema upotrebi vulgarizama suzdržani ${ }^{9}$ i oni, brojniji, koji u većoj meri upotrebljavaju pomenuti vulgarizam u svojim delima ${ }^{10}$.

Prelazeći na centralni deo našeg rada, na vulgarizam "cazzo“, ispitaćemo koji su prevodni ekvivalenti u srpskom jeziku usvojeni za ovu reč. Naše istraživanje sproveli smo na četiri romana Federika Moče i na njihovim prevodima na srpski jezik: Želim te, Taj trenutak sreće, Izvini ali hoćeš li da se udaš za mene?, Izvini ali ti si moja ljubav $^{11}$ (u daljem tekstu navodićemo samo dve reči iz naslova). Vulgarizam „cazzo“ (i oblik množine „cazzi“) javlja se sa sledećom distribucijom:

\begin{tabular}{|c|c|c|c|c|c|}
\hline Roman: & Želim te & Taj trenutak & Izvini... oženim & Izvini... ljubav & Ukupno \\
\hline cazzo & 98 & 43 & 8 & 58 & 207 \\
\hline cazzi & 3 & 4 & & & 7 \\
\hline
\end{tabular}

Samo u dva slučaja pomenuti vulgarizam je upotrebljen u denotativnom značenju:

[1] „ „(..) è la favola di una prostituta.“

„Ci sono: Biancaneve e i sette cazzi.“

„(...) to je bajka o jednoj prostitutki.“

„Znam: Snežana i sedam kurčeva."(Želim te $31,8 \%)^{1}$

[2] „Sai che ci faccio io con il tuo limoncello? Mi ci pulisco il cazzo.“ „Je l’ znaš šta ću ja da uradim sa tvojim limončelom? Opraću sebi kurac!" (Želim te 32\%) ${ }^{2}$

9 Kod Umberta Eka, u 10 dela vulgarizam „,cazzo“ se javlja u tri dela od ukupno pet (skraćeno: 10/3/5), koliko smo pregledali; slična situacija je kod Klaudija Magrisa (6/1/2) i Sebastijana Vasalija (12/4/4).

10 Pregledali smo dela Andree De Karla (19/8/181), Nikoloa Amanitija (10/6/272), Stefana Benija (21/9/77) i Fabija Vola (9/8/188): brojke potvrđuju da vulgarizam „cazzo“ u izrazu ovih pisaca ima stabilno mesto - što može da govori u prilog činjenici da oni u većoj meri prisvajaju obrasce govornog jezika.

11 Redom: Ho voglia di te (2006), prevela Biljana Janković; Quell'attimo di felicità (2013), prevela Svetlana Novaković; Scusa ma ti voglio sposare (2009), prevela Biljana Janković; Scusa ma ti chiamo amore (2007), prevela Biljana Janković. 
Alternativno, kada autor želi da uputu na muški ud, upotrebljava žargonski izraz „uccello“ (doslovno: „ptica“), i to samo u jednini. Na ostalim mestima reč „cazzo“ je upotrebljena kao samostalni uzvik, u funkciji postizanja emfaze u upitnoj ili uzvičnoj rečenici ili kao deo idiomatskih izraza, što ćemo izložiti malo niže.

Predmetni italijanski vulgarizam, pored frekvencije upotrebe, pokazuje i određenu rekurzivnost, na koju prevodioci Močinih romana na nekim mestima reaguju tako što predlažu nemotivisano varirane leksičke ekvivalente vulgarizma „cazzo“. Ovakvo postupanje je uočljivo u mikrokontekstima u kojima ponavljanje ove reči deluje funkcionalno, bilo da je reč o insistiranju na uniformnoj verbalizaciji neke emotivne reakcije, bilo da je reč o reprodukovanju jezičke jednoobrazonosti i uprošćenosti kada je u pitanju iskazivanje emocija i komuniciranje uopšte. Nekoliko sledećih primera može da ilustruje rekurzivnost vulgarizma "cazzo" i neopravdanost njenog proizvoljnog variranja:

[3] Cazzo, mi manca l'aria. (...). Faccio appena in tempo ad alzarmi che vedo calare da destra il suo guantone. (...). Ma mi colpisce di striscio spaccandomi il labbro inferiore. Cazzo. Cazzo.

Sranje, treba mi vazduha. (...). Stižem jedva na vreme da se podignem i vidim kako se zdesna spušta njegova rukavica. (...). Ali me zakači i cepa gornju usnu. U kurac! U kurac! (Želim te, 36\%)

[4] E dai, cazzo. Cazzo.

Ma daj, jebote. U kurac! (Izvini...ljubav, 67\%)

[5] „Cazzo che incubo! Che incubo, cazzo!"

„Jebote, kakva mora! Kakva mora, sranje!“ (Želim te, 45\%)

U prevođenju pomenutog vulgarizma prihvatljivi su postupci dizlokacije i kompenzacije: vulgarizam se čuva u prevodu, ali se pomera na mesto gde se on uklapa u srpski tekst, mada je ovaj u pogledu stila i ekspresivnosti nešto napadniji od italijanskog teksta:

[6] Vuol dire che non capisci un cazzo e che ti vesti pure male.

Znači da ništa ne razumeš i da ti oblačenje nije ni za kurac. (Izvini... ljubav, 83\%) 
U analiziranim delima zabeležene su sledeće upotrebe vulgarizma „cazzo“ u množini:

- u službi odbijanja pomoći: cazzi tuoi:

[7] Be', saranno cazzi tuoi (...).

Ma, tvoja stvar, zabole me (...). (Taj trenutak..., 19\%)

[8] Sono cazzi tuoi (...).

To su tvoja sranja (...). (Taj trenutak..., 20,8\%)

[9] Sono cazzi tuoi...

Ma zabole me, tvoj problem... (Taj trenutak..., 36,4\%)

- za izražavanje negodovanja: 'sti cazzi:

[10] E 'sti cazzi! Nosi se! (Želim te, 60,8\%)

- u službi negacije: mica cazzi:

[11] Cioè, tuo padre era un pezzo forte in quella casa, mica cazzi. Mislim, tvoj otac je bio veoma bitan činilac u toj kući, nije to za zajebavanje. (Želim te, 25,4\%)

U navedenim slučajevima u prevodima je sačuvana ublažena, desemantizovana vrednost italijanskog vulgarizma i na onim mestima (uz glagol „zaboleti“, pr. [7] i [9]) gde je postojala mogućnost da se ovaj idiomatski izraz dopuni srpskim vulgarizmom („zabole me kurac") i da se na taj način u tekst prevoda unese veća mera vulgarnosti od one koja postoji u originalu.

Kada je reč o upotrebama italijanskog vulgarizma „cazzo“ u jednini, one su prikazane u sledećoj tabeli. Izraz se javlja:

1. u službi samostalnog uzvika, s ukupno 129 primera i sa sledećom distribucijom:

\begin{tabular}{|c|c|c|c|}
\hline Izvini...ljubav & Izvini...udaš & Želim te & Taj trenutak \\
\hline 36 primera & $6 \mathrm{pr}$. & $64 \mathrm{pr}$. & $23 \mathrm{pr}$. \\
\hline
\end{tabular}

Ovaj vulgarizam se najviše javlja u službi samostalnog uzvika, u najrazličitijim situacijama; on naglašava osećanja poput ljutnje, razočaranosti, iznenađenja itd. S obzirom na raznovrstnost upotre- 
be, u prevodima na srpski je upotrebljeno više ekvivalenata. To je razlog da ih detaljnije izložimo:

a) izraz ,jebote“ upotrebljen je 49 puta; njegova distribucija je, prema redosledu kolona u gornjoj tabeli: 16-18-3-12):

[12] Cazzo, pure tu.

Jebote, i ti. (Izvini...udaš? 42\%)

b) izraz „sranje“ upotrebljen je 33 puta; njegova distribucija je, redom: 24-0-0-9:

[13] Ce l'ho stampata sul cuore quella chiacchierata, come fosse ieri, cazzo. Sranje, taj razgovor urezao sam u mozak, kao da je bio juče. (Izvini... ljubav, 2\%)

[14] Cazzo, cazzo, cazzo.

Sranje, sranje, sranje. (Izvini...ljubav, 20\%)

c) izraz ,jebiga“ upotrebljen je 20 puta; njegova distribucija je, redom: 12-0-3-5:

[15] Non è così che si reagisce alle cose! Cazzo!

Ne reaguje se tako na stvari! Jebiga! (Izvini...udaš? 43\%)

d) izraz „u kurac“ upotrebljen je18 puta; njegova distribucija je, redom: 3-5-0-10:

[16] „Hai il mio disprezzo sentimentale, cazzo!“, le urla dietro Alessandro. „Imaš moje sentimentalno omalovažavanje, u kurac!“ Alesandro urla iza nje. (Izvini... ljubav, 2\%)

[17] Cazzo, cazzo, cazzo.

U kurac, u kurac, u kurac. (Izvini...ljubav, 20\%)

e) izraz „koji kurac“ upotrebljen je tri puta (njegova distribucija je:1-0-0-0; za druge primere, vidi primere [61]-[65]): 
[18] E che cazzo!

Ma šta, koji kurac! (Izvini...ljubav, 77\%)

f) izraz „do đavola“ upotrebljen je dva puta; njegova distribucija je, redom: 2-0-0-0:

[19] Cazzo, quanti fiori mandati da quel fioraio, quello che fa più sconti di tutti. Do đavola, koliko sam cveća poslao iz ove jeftine cvećare. (Želim te, 8,5\%)

g) vulgarizam „cazzo“ nije preveden dva puta (distribucija: 2-0$0-0)$ :

[20] Dai vieni, cazzo, farà piacere a tutti rivederti. Hajde, dođi i ti, svi će se radovati što te vide. (Želim te, 19\%)

[21] Ti giuro, cazzo, è allegra, simpatica, intelligente, è forte. Kunem ti se, vesela je, simpatična, inteligentna, duhovita. (Želim te, 46\%)

h) izraz „koji đavo“ upotrebljen je jednom (distribucija: 1-0-0-0):

[22] Ehi, cazzo Step, che succede? Šta se, koji đavo, dešava? (Želim te, 61\%)

i) izraz „u pizdu materinu“ upotrebljen je jednom (distribucija: 1-0-0-0):

[23] Cazzo e vaffanculo. U pizdu materinu. (Želim te 45\%)

j) izraz „čoveče“ upotrebljen je jednom (distribucija: 1-0-0-0):

[24] Cazzo, che balzo che ha fatto quando si è svegliato sentendosi bruciare. Čoveče, kako je skočio kad se probudio osetivši da gori. (Želim te, 45\%)

Navedeni numerički pokazatelji upućuju na zaključak da su prevodioci Močinih dela u najvećem broju slučajeva (108/129: redom, tačke $a, b, c, f, g, h$ i $j$ ) upotrebili kao ekvivalent italijanskog 
vulgarizma „cazzo“ desemantizovane srpske vulgarizme (odnosno, u dva slučaja - tačke $h$ i $j$ - neutralniizraz „koji đavo“ i reč „čovek“ ) koji postižu sličan efekat prihvatljivosti kao italijanski izraz. U tačkama $d, e$ i $i(21 / 129)$ čini se da prevod ostavlja snažniji utisak vulgarnosti (mada se on, u tački $i$, može smatrati i opravdanim, zbog upotrebe dva vulgarna izraza jedan do drugog): takav utisak može da utiče na drugačiju percepciju ne samo likova ovih romana već $\mathrm{i}$ samog autora i njegovih intencija. Ipak, imajući u vidu činjenicu da su ovakvi primeri u manjini, može se reći da su prevodioci u slučaju najfrekventnije funkcije reči „cazzo“ postupili obazrivo i da su imali u vidu prvenstveno pragmatičku vrednost i socio-kulturnu prihvatljivost njenih srpskih ekvivalenata.

2. u emfatičkoj službi. Zabeleženo je ukupno 38 primera, i to posle: „che“ (10), „chi“ (9), „come“ (10), „cosa“ (1), „dove“ (7), „quando" (1), sa sledećom distribucijom po delima:

\begin{tabular}{|l|l|l|l|}
\hline Izvini...ljubav & Izvini... udaš & Želim te & Taj trenutak \\
\hline a) che $\sim 2$ & che $\sim 0$ & che $\sim 6$ & che $\sim 2$ \\
b) chi $\sim 1$ & chi $\sim 0$ & chi $\sim 6$ & chi $\sim 2$ \\
c) come $\sim 2$ & come $\sim 1$ & come $\sim 6$ & come $\sim 1$ \\
d) cosa $\sim 0$ & cosa $\sim 0$ & cosa $\sim 0$ & cosa $\sim 1$ \\
e) dove $\sim 2$ & dove $\sim 0$ & dove $\sim 1$ & dove $\sim 4$ \\
f) quando $\sim 1$ & quando $\sim 0$ & quando $\sim 0$ & quando $\sim 0$ \\
\hline
\end{tabular}

U emfatičkoj službi vulgarizam „cazzo“ posle navedenih upitnih zamenica ili priloga pojačava afektivnu dimenziju pitanja koja se uvode na ovaj način. Vulgarizam nije upotrebljen samostalno već kao dodatni, sekundarni element; stoga bi se moglo pretpostaviti da on, u ovoj sporednoj semantičkoj ulozi, ne proizvodi neprihvatljivu reakciju i odbojnost kod sagovornika. Njegovi prevodni ekvivalenti su, prema redosledu prethodne tabele: 
(a) che cazzo:

[25] Ma che cazzo c'avrà da ridere? Ma šta je ovde smešno? (Želim te,16,7\%)

[26] Gin, che cazzo succede? Đin, šta se, do đavola, dešava? (Želim te, 42\%)

[27] Che cazzo c'avete da guardare, giocate giocate... Koji kurac gledate?! Igrajte, igrajte... (Izvini...ljubav, 59,6\%)

[28] Ma che cazzo tocchi, eh? Ma koji kurac to diraš? (Želim te, 32,3\%)

[29] E te, che cazzo vuoi? A koji kurac ti 'oćeš?! (Želim te, 60\%)

[30] Ma che cazzo fai? Šta radiš koji kurac? (Taj trenutak, 94\%)

Samo u prva dva slučaja prevodni ekvivalent zadržava neutralnu vrednost, dok u drugim primerima srpski vulgarni izraz je manje prihvatljiv u pogledu njegove socio-kulturne dimenzije. Preporuka bi bila da se upotrebi neki neutralniji ekvivalent, npr. „jebote“, ili - gde je to zgodno - uzvik „bre“.

\section{(b) chi cazzo:}

[31] (...) chi cazzo l'ha portata la coca a casa mia?

(...) ko je, u kurac, doneo kokain u moju kuću?! (Izvini...ljubav, 8,9\%)

[32] Perché, chi cazzo sono? Zašto, koji sam ja kurac? (Želim te, 29\%)

[33] Chi cazzo lo conosce... Ko ga, koji kurac, poznaje... (Želim te, 34\%)

[34] Ahia, ma chi cazzo è stato? Jao, ma koji je to kurac bio? (Želim te, 34\%)

[35] Ma chi cazzo era quello lì? Ma, koji je kurac ovaj ovde? (Želim te, 44,5\%)

[36] „E tu chi cazzo sei?" „Uno che passava di qui per caso. E tu invece, chi cazzo pensi di essere?“ "A ko si sad pa ti?!“ „Neko ko je slučajno prolazio. A ti, koji kurac, misliš da si ti?““(Želim te, 27\%) 
Kao što se vidi iz gorenavedenih primera, vulgarna sintagma „chi cazzo" uglavnom je prevođena neprimereno napadnim srpskim vulgarizmom. Samo u poslednjem primeru [36] uočava se ublažavanje vulgarnog efekta („A ko si sad pa ti?!“), ali na uštrb koherentnosti samog dijaloga. Naime, već u sledećoj rečenici drugi sagovornik upotrebljava izraz „koji kurac“ i time se oni ne svrstavaju na istu ravan već zauzimaju različite verbalne pozicije pred fizički sukob. U prevodu se uspostavlja asimetrija pristojno : nepristojno koja u originalnom tekstu ne postoji. Kod Moče, kao što se vidi u primeru [36], oba sagovornika primenjuju isti - vulgarni - pristup u komunikaciji.

c) come cazzo:

[37] (...) Un grandissimo stronzo, Fabio Fobia, o come cazzo ti chiami (...) Ogromno đubre, Fabio Fobija, ili kako se već koji kurac zoveš (Izvini...ljubav, 55\%)

[38] Tu non fai come cazzo ti pare! Nećeš se ti, u kurac, ponašati kako ti se digne! (Izvini...ljubav, 62,5\%)

[39] Ma come cazzo guidi? Ma kako to, koji kurac, voziš? (Izvini...udaš, 20,7\%)

[40] Pietro, o come cazzo si chiama, ha la bocca aperta (...) Pjetro, ili kako se već, koji kurac, zove, diše otvorenih usta (...) (Želim te, 27,3\%)

[41] Come cazzo fanno due uomini a non vergognarsi (...) Kako se ova dvojica ne stide (...) (Želim te,18\%)

[42] Allora Stefano, o Step o come cazzo ti pare, hai voglia di litigare? $\mathrm{Pa}$, Stefano, ili Step, ili kako god želišs, hoćeš da se svađaš? (Želim te, $18 \%)$

[43] Ma come cazzo hai fatto a metterti con una così, Step!!! Ma, kako si samo mogao da se smuvaš sa takvom, Step!!! (Želim te, $96 \%$ )

U ovom slučaju italijanski vulgarni izraz preveden je desemantizovanim ekvivalentom samo u poslednja tri primera, dok je u preostalih pet emfatični upitni izraz „come cazzo“ preveden socio-kulturno manje prihvatljivim srpskim vulgarizmom. Ipak, za si- 
tuaciju koja je ambijentirana u saobraćaju (primer [39]) prevodiočevo opredeljenje je bliže jezičkoj praksi kojoj smo svedoci u Srbiji ${ }^{12}$.

d) cosa cazzo:

[44] Io vorrei sapere cosa cazzo ho fatto in tutto questo tempo. Ja hoću da znam šta sam koji kurac radila sve ovo vreme. (Taj trenutak, 265/283)

e) dove cazzo:

[45] Ma dove cazzo sei stato finora, eh? Ma gde si koji kurac bio dosad, a? (Taj trenutak, 54/283 )

[46] Vale, dove cazzo sei, scendi! Vale, gde si, koji kurac, silazi! (Taj trenutak, 59/283 )

[47] Ma dove cazzo eri finito? Ma gde si, koji kurac, zaglavio!? (Želim te, 94/424)

I u ovim primerima usvojeni srpski ekvivalent uvodi neodmeren vulgarni ton u komunikaciju. Upotreba desemantizovanih alternativa (npr. „jebote“, na početku ili na kraju iskaza; u primeru [46] deo emfatičnosti mogao se preneti na glagol „silaziti“ - „silazi više!") preciznije bi prenela relativno neutralnu atmosferu koju odslikavaju italijanski dijalozi. Upotreba srpskog vulgarizma „koji kurac" doprinosi stvaranju utiska da među sagovornicima postoji veća tenzija i netrpeljivost nego u originalnom tekstu.

f) quando cazzo:

[48] Ma quando cazzo mi ricapita una russa così (...). Kad će mi, koji kurac, opet naleteti jedna ovakva Ruskinja (...) ? (Izvini...ljubav, 45/627)

12 Umanjena fluentnost celog srpskog iskaza ipak govori u prilog činjenici da je prevodilac morao da obrati pažnju i na ovu dimenziju iskaza, na njenu efektivnu izgovorljivost. Verovatnije je da bi se srpski vozač obratio drugom vozaču rečima „Kako voziš, jebote/konju jedan“ ili sl. 
I za primer [48] mogu se ponoviti već iznesene primedbe vezane za smanjenu fluentnost iskaza i za neprimerenost usvojenog socio-kulturnog registra u srpskom prevodu. I u ovom slučaju izraz „jebote“ bi zadovoljio oba zahteva.

3. u službi negacije (...un cazzo). Zabeleženo je ukupno 17 primera, sa sledećom distribucijom:

\begin{tabular}{|c|c|c|c|}
\hline Izvini...ljubav & Izvini... udaš & Želim te & Taj trenutak \\
\hline 6 & & 5 & 6 \\
\hline
\end{tabular}

Vulgarizam „un cazzo“ ima značenje „ništa“, „ni malo“; upotrebljava se kao drugi član negacije, obično umesto priloga "niente“/ „nulla“ (npr. „non me ne importa niente“). Njegov prevodni ekvivalent je, u navedenim primerima, srpska vulgarna reč „kurac“ koja je, u funkciji pojačavanja negacije, prisutna u tekućoj upotrebi. Naša vulgarna reč se po komunikativnoj dimenziji sasvim podudara $\mathrm{s}$ italijanskim vulgarizmom; ostaje, načelno, primedba da se i ovde u srpskom prevodu oseća veća mera vulgarnosti nego u italijanskom. Sa druge strane, teško se može naći neki drugi ekvivalent kao socio-kulturno prihvatljivija alternativa za italijanski izraz:

[49] Tutto a posto un cazzo! Kurac je sve u redu! (Želim te, 27\%)

[50] E poi dicono che i soldi possono tutto. Non possono un cazzo! I posle kažu da kad imaš pare možeš sve. Možeš moj kurac! (Taj trenutak, $3,5 \%)$

[51] Niente, oh, laggiù non si vede un cazzo, è tutto buio. Ništa, o, tamo dole se ne vidi ni kurac, sve je mračno. (Taj trenutak, 42\%)

[52] Vabbè, allora da oggi io non ti racconto più un cazzo. Važi, e znači od danas ću ti kurac moj ispričati. (Taj trenutak, 70\%)

[53] Con calma un cazzo. Kurac moj, na miru! (Želim te, 43,8\%)

Izmeštanje ekvivalentnog vulgarizma uz drugi glagol, predstavlja prihvatljivo rešenje i proizvodi strukturu koja je frekventna u savremenom kolokvijalnom jeziku: 
[54] Vuoi dire che non capisci un cazzo e che ti vesti pure male. Znači da ništa ne razumeš i da ti oblačenje nije ni za kurac. (Izvini... ljubav, 67\%)

Povodom pomenute rekurzivnosti nekog izraza u originalnom tekstu i neophodnosti da se on prevede jednoobrazno (vidi gore, primere [3]-[5]), zanimljiv je sledeći primer. Prevodilac propušta priliku da i četvrti put ponovi vulgarizam za koji se opredelio protagonista. Ovaj, naime, uporno ponavlja, služeći se vulgarnim izrazom, kako nije „dovoljno vredan“. Čini se da je translatološki bilo dragoceno sačuvati ovaj produženi izliv očaja u integralnom obliku, ne remeteći njegovu leksičku rekurzivnost i koherentnost:

[55] Non conto un cazzo. Non conto proprio un cazzo. Per lei io non conto un cazzo, non ho mai contato un cazzo.

Nisam ni za kurac. Baš nisam ni za kurac. Za nju ja nisam ni za kurac, nikad i nisam ništa predstavljao. (Izvini...ljubav, 91,5\%)

U narednim primerima upotrebljeni su eufemistički izrazi, dok su u poslednja dva ti izrazi potpuno neutralni. Razlog za odbacivanje srpskog leksičkog ekvivalenta leži u činjenici da se on u ovakvim iskazima ne upotrebljava, te bi njegova primena u prevodu proizvela neuobičajene i za srpski jezik isforsirane strukture:

[56] Oh, non c'è un cazzo da fare, eh...

0, ne može se tu jebeno ništa, e... (Taj trenutak, 70\%)

[57] ...anche se non sai un cazzo per noi va benissimo così. ...čak i ako nemaš jebenog pojma, nama je ovako baš super. (Taj trenutak, 37\%)

[58] Non c'è un cazzo da fare. Nikakvo sranje im ne pomaže. (Želim te, 36,7\%)

[59] Io sono la signora Gervasi. E tu, tu non sei un cazzo! Ja sam gospođa Đervazi. A ti, ti nisi ništa! (Želim te, 88\%)

[60] Non c'entra un cazzo ma l'ho visto in un filmato in tv. Nema nikakve veze sa ovim, ali video sam u jednom dokumentarcu na TV-u. (Izvini....jubav,36,3\%) 
ITALIJANSKI VULGARIZAM „CAZZO“ I NJEGOVO PREVOĐENJE NA SRPSKI JEZIK

4. u službi samostalnog uzvika che cazzo. Zabeleženo je ukupno šest primera, s ovom distribucijom:

\begin{tabular}{|c|c|c|c|}
\hline Izvini...ljubav & Izvini... udaš & Želim te & Taj trenutak \\
\hline 2 & 1 & 1 & 2 \\
\hline
\end{tabular}

Vulgarizam „e che cazzo“, kojim se izražava nestrpljenje, preveden je izrazima koji u srpskom deluju napadnije, ali se čuju u kolokvijalnom jeziku. Alternativa ,jebiga“ (ili ,jebote“), kao u [65] mogla bi proizvesti adekvatnu eufemizaciju drugih prevoda:

[61] E che cazzo !

I šta koji kurac! (Izvini...ljubav, 17,8\%)

[62] E che cazzo!

I šta, koji kurac! (Želim te, 52.5\%)

[63] E che cazzo!

Ma šta, koji kurac! (Izvini...ljubav, 77,5\%)

[64] E che cazzo!

Ma do kurca! (Taj trenutak, 66,7\%)

[65] E che cazzo!

Jebiga! (Izvini...udaš, 44,8\%)

5. u atributskoj službi (u strukturi DET. cazzo DI). Zabeleženo je ukupno četiri primera, sa sledećom distribucijom:

\begin{tabular}{|c|c|c|c|}
\hline Izvini...ljubav & Izvini... udaš & Želim te & Taj trenutak \\
\hline 3 & & & 1 \\
\hline
\end{tabular}

Vulgarizam „DET cazzo DI“ (u atributskoj službi) javlja se četiri puta u dva Močina romana. Ovaj vulgarizam ima posebnu frazeološku dimenziju i njegovi prevodni ekvivalenti su, čini se, pažljivo odabrani. Izbegnut je eventualni leksički ekvivalent „kurčev“, koji nije desemantizovan i u navedenim funkcijama nije široko usvojen u kolokvijalnom jeziku: samim time u prevodu bi zvučao prenapadno. Možda je, u poslednjem primeru, mogao da se aktivira neki drugi izraz („to govno od kotura“, ili „taj glupi kotur“): 
[66] Sei sempre stata brava con 'ste cazzo di frasi. Uvek si bila dobra s tim jebenim frazama. (Izvini...ljubav, 62,5\%)

[67] Quel cazzo di cellulare ce l'hai sempre in tasca. Ovaj jebeni mobilni ti je stalno u džepu. (Izvini...ljubav, 64\%)

[68] Siamo state noi a farla tornare! Se era per quei cazzo di medici. Mi smo je povratile! Da nisu možda oni jebeni doktori! (Izvini...ljubav, $77,6 \%)$

[69] (...) e vedevo quel cazzo di tondello abbandonarmi (...)

(...) i video onaj jebeni kotur kako se udaljava (...) (Taj trenutak, $31,7 \%)$

6. u idiomatskom izrazuu službi negacije: „(non) fregarne un cazzo a qcn“. Zabeleženo je ukupno šest primera, sa sledećom distribucijom:

\begin{tabular}{|c|c|c|c|}
\hline Izvini...ljubav & Izvini... udaš & Želim te & Taj trenutak \\
\hline 3 & & 2 & 1 \\
\hline
\end{tabular}

Glagol „fregare“sadrži obeležje vulgarnosti zbog nepristojnog gesta kojim je propraćen (izgovarajući ga - „me ne frego“ -govornik može da prisloni ruku na regiju polnog organa i da zauzme izazivački stav; istovetan gest postoji i kod govornika srpskog jezika). Njegovi prevodni ekvivalenti u prva četiri primera deluju vulgarnije od italijanskog izraza i pogađaju naš jezički osećaj, koliko god da su oni upotrebljeni uobičajeni (u primeru [70] bio je dovoljan glagol „zaboleti“). U preostala dva primera prevod je neutralniji i više odgovara desemantizovanoj vrednosti imenice „cazzo“:

[70] Ma che cazzo me ne frega di chi te l'ha data. Ma šta me koji kurac zabole za onog ko ti je dao! (Izvini...ljubav, $8,9 \%)$

[71] Che cazzo te ne frega, Bama, eh? Šta te boli kurac, Bama? (Izvini...ljubav, 67,3\%)

[72] Embè, a me che cazzo me ne frega? $\mathrm{Da}$, i šta mene to koji kurac interesuje? (Taj trenutak..., 21\%)

[73] A quella nun gliene frega un cazzo de te! Toj tamo se živo jebe za tebe! (Izvini...ljubav, 71\%) 
[74] Non me ne frega un cazzo.

Boli me uvo. (Želim te, 30\%)

[75] E basta Step, che cazzo te ne frega?

Ma, dosta, Step, šta te briga? (Želim te, 61,3\%)

7. u idiomatskom izrazu: „stare sul cazzo a qcn.“ („nervirati nekoga"). Zabeležena su ukupno tri primera, sa sledećom distribucijom:

\begin{tabular}{|c|c|c|c|}
\hline Izvini...ljubav & Izvini... udaš & Želim te & Taj trenutak \\
\hline & & 3 & \\
\hline
\end{tabular}

Vulgarni frazeološki izraz „stare sul cazzo a qcn.“ prevođen je srpskim vulgarnim izrazom „ići na kurac“, mada se i u ovom slučaju stiče utisak da je srpski izraz manje prihvatljiv od italijanskog (što je, opet, posledica desemantizacije italijanskog vulgarizma). Drugih, pogodnijih i jednako efektnih izraza, sa druge strane, čini se da nema (izrazi "ne mogu da smislim“, „ne mogu očima da vidim“ nisu dovoljno ekspresivni da bi bili ekvivalenti italijanskog izraza „stare sul cazzo"):

[76] Quello lì mi stava sul cazzo, tutto qua.

Taj tip mi je, jednostavno, išao na kurac, to je sve. (Želim te, 4,5\%)

[77] Mi stanno sul cazzo.

Ionako mi idu na kurac. (Želim te, 75\%)

[78] Mi sono sempre stati sul cazzo tutti e tre.

Ionako su mi išli na kurac, sva trojica. (Želim te, 78,3\%)

8. u idiomatskom izrazu: „rompere il cazzo (a qcn.)", „dosaditi/dosađivati nekome“. Zabeležena su dva primera, sa sledećom distribucijom:

\begin{tabular}{|c|c|c|c|}
\hline Izvini...ljubav & Izvini... udaš & Želim te & Taj trenutak \\
\hline & & 1 & 1 \\
\hline
\end{tabular}

Ovaj izraz je frekventan u italijanskom jeziku, bilo da se javlja bez direktnog objekta (samo kao „non rompere“ - „ne dosađuj“, „, ne 
Saša Moderc, Maurizio Barbi

smaraj"), bilo da mu sledi eufemizam (npr. „scatole“) ili druga vulgarna reč:,,coglioni“ (,jaja“, „testisi“), odnosno, kao u sledećim primerima, reč „cazzo“:

[79] „E muoviti, che hai rotto il cazzo!“ La ragazza prova a dire qualcosa, ma non fa in tempo.

„Mrdaj, kurvetino!“ Devojka zausti nešto da kaže, ali nema vremena. (Želim te, 60,5\%)

[80] Già me l'hai detta 'sta cosa dei principi. Mi ha rotto il cazzo, passamela...

Već si mi rekao za to s principima. Smorila me je do jaja, daj mi je... (Taj trenutak, 54,4\%)

U prvom primeru prevodilac kompenzuje neprevedeni italijanski izraz tako što prebacuje vulgarnost na plan lične diskvalifikacije („kurvetino“), što se čini kao uspešno prevodilačko rešenje. Glagol „smoriti“ u drugom primeru takođe je dobar ekvivalent italijanskog izraza jer se s njime podudara i po značenju i po zastupljenosti u govornom jeziku.

9. u idiomatskom izrazuu službi negativne kvalifikacije osobe: „testa di cazzo“. Zabeležen je jedan primer:

\begin{tabular}{|c|c|c|c|}
\hline Izvini...ljubav & Izvini... udaš & Želim te & Taj trenutak \\
\hline & & 1 & \\
\hline
\end{tabular}

Vulgarni izraz „testa di cazzo“(„glupan“, „budala“) preveden je na sledeći način:

[81] Hai capito, testa di cazzo?

Jesi li razumeo, seronjo?! (Želim te, 32,3\%)

Čini se da bi neki drugi ekvivalent bio upečatljiviji, poput „majmune" ili, „pičko“; naime, na ovom mestu u romanu Želim te opisuje se fizički sukob dva muškarca i ova druga rešenja bi realističnije odslikala verbalnu razmenu pred fizički obračun. 
10. u idiomatskom izrazu: „(fare qcs.) a cazzo“, „(uraditi nešto) nemarno“. Zabeležen je jedan primer:

\begin{tabular}{|c|c|c|c|}
\hline Izvini...ljubav & Izvini... udaš & Želim te & Taj trenutak \\
\hline & & 1 & \\
\hline
\end{tabular}

Ovaj izraz preveden je na sledeći način:

[82] E uso la cucitrice „a cazzo“...

I heftalicu koristim preko kurca... (Želim te, 78\%)

Gornji primer sadrži igru reči: naime, protagonista upotrebljava heftalicu da povredi penis već savladanog egzibicioniste, te se prevod može smatrati ekvivalentnim odgovarajućim u pogledu opisane situacije. Inače, priloški izraz „a cazzo“ zapravo označava nemarno izvedenu radnju; srpski ekvivalent „preko kurca“ objedinjuje i preneseno značenje, „nevoljno“ i, ovde, prostorno značenje (upućuje na mesto, prostor ne kome se vrši radnja heftanja: koža penisa).

11. kao upitna zamenica. U ovoj službi vulgarizam „cazzo“ zabeležen je jednom:

\begin{tabular}{|c|c|c|c|}
\hline Izvini...ljubav & Izvini... udaš & Želim te & Taj trenutak \\
\hline & & 1 & \\
\hline
\end{tabular}

Italijanski vulgarizam poprima navedenu funkciju usled elipse upitnih zamenica che? (kao u sledećem primeru) ili chi?, koje mu prethode. U socio-kulturnom pogledu, prevod zvuči manje prihvatljivo u odnosu na original:

[83] Cazzo c'hai da ridere, vuoi fare a stecche?

Šta je, koji kurac, smešno? Hoćeš da se bijemo palicama? ${ }^{3}$ (Želim te, $24,7 \%$ )

Utisak naglašenije vulgarnosti prevoda mogao se ublažiti kompenzacijom, odnosno prebacivanjem vulgarnog elementa na ličnu 
Saša Moderc, Maurizio Barbi

kvalifikaciju sagovornika, npr.: „Šta je smešno, majmune/pičko“ (slično kao u primeru[79]).

12. u službi negacije, u vidu izraza „col cazzo“. Ovaj izraz javlja se jednom:

\begin{tabular}{|c|c|c|c|}
\hline Izvini...ljubav & Izvini... udaš & Želim te & Taj trenutak \\
\hline & & 1 & \\
\hline
\end{tabular}

Izraz je preveden na sledeći način:

[84] Col cazzo che fai benzina coi soldi miei!

Mojim parama sipaš benzin, seronjo! (Želim te, 24,7\%)

Za opisanu konfliktnu situaciju trebalo je upotrebiti srpski izraz koji bi vernije odslikao verbalnu reakciju izvornog govornika srpskog jezika, npr. „Kurac ćeš sipati benzin mojim parama!“. Mada se srpski izraz može učiniti vulgarnijim u odnosu na desemantizovani italijanski ekvivalent, upravo je ovo rešenje prikladnije za datu situaciju (moguća su i druga rešenja, od „malo sutra“ do „('oćeš) kurac"; u svakom slučaju, u konfliktnoj situaciji većina izvornih govornika srpskog jezika pre bi oslovilo sagovornika sa „pederu“ nego sa „seronjo“, ili bi udenula u svoje obraćanje neke vulgarne izraze koji se grade oko imenica „majka“ ili „mater").

13. u atributskoj službi, u izrazu „del cazzo“. Zabeležen je jedan primer:

\begin{tabular}{|c|c|c|c|}
\hline Izvini...ljubav & Izvini... udaš & Želim te & Taj trenutak \\
\hline & & 1 & \\
\hline
\end{tabular}

Ovaj izraz preveden je na sledeći način:

[85] Un trucco di qualche piottaro del cazzo che vuole fare il pieno alla faccia mia.

Prevara nekog jebenog kučkinog sina koji preda mnom hoće da napuni rezervoar. (Želim te, 24,7\%) 
Dok sintagmu „piottaro del cazzo“ krasi određena artikulaciona fluentnost, srpski ekvivalent „jebenog kučkinog sina“ zvuči sinkopirano i napadnije nego originalni izraz. Na stranu ovaj fonetski aspekt, termin rimskog dijalekta "piottaro“ označava škrtu ili nemarnu osobu ${ }^{13}$, a kako je u ovom slučaju reč o pokušaju izvršenja sitnije krađe ${ }^{14}$, italijanskoj reči bi pre odgovarao srpski izraz ,jajara“. Dakle, „piottaro del cazzo“ moglo je da se prevede kao „(glupa) jajara“, „bednik“ ili sl., čime bi se u prevod uključilai dimenzija prezira, gledanja sa visine, koja je prisutna u italijanskom tesktu.

\section{Zaključak}

Romani Federika Moče predstavljaju primer širokog prodora vulgarnih izraza u jezik savremene književnosti. Pitanje književne vrednosti Močinih dela može biti predmet rasprave, ali nesporna je činjenica da njegovi romani uživaju veliku popularnost; samim tim mogu da doprinesu da se modeli i leksika iz kolokvijalnog jezika dalje šire u jezik književnosti. Približavanje kolokvijalnog jezika i jezika književnosti nije odlika samo Močine proze, kako smo uzgredno pokazali u ovom radu: takav izbor čine i drugi savremeni autori. U ovom radu ne možemo da se osvrnemo na dublje, kulturne i sociolingvističke razloge za ovakav jezički i kulturološki pomak kod jednog dela italijanskih pisaca. Ono što možemo da kažemo jeste da takav pomak ne bi bio moguć da mnogi italijanski vulgarizmi nisu prethodno prošli kroz proces desemantizacije, odnosno slabljenja efekta neprihvatanja i odbojnosti koji mogu da proizvedu kod drugih učesnika u komunikaciji. Na ovom prostoru nije moguće rekonstruisati procese koji su uslovili da se neki vulgarni izrazi danas u Italiji smatraju manje neprihvatljivim (kao reč „cazzo“,

13 Up. definiciju: „persona meschina, avara o comunque di basso livello umano e/o professionale“. Vidi: https://www.lamoneta.it/topic/14025-lorigine-della-piotta/.

14 Situacija iz navedenog primera bila bi jasnija da je prevodilac pažljivije preveo izraz „alla faccia mia“, koji ovde nema lokativnu dimenziju („preda mnom“) već ima značenje „na moj račun“, „za moje pare“. Reč je, da pojasnimo, o sukobu ispred automatizovane pumpe za točenje goriva. 
Saša Moderc, Maurizio Barbi

ali i mnoge druge, koje se sve manje doživljavaju kao vulgarizmi), dok se istovremeno neki vulgarizmi i dan-danas doživljavaju kao tabu (na primer, blasfemični izrazi su najmanje prihvatljivi, kako u jezičkim anketama, tako i u intimnom osećaju Italijana uopšte: međutim, takva percepcija blasfemije gotovo sigurno ne proističe iz iskrene pobožnosti).

Prevođenje Močinih romana postavlja prevodioca pred zadatak da italijanske vulgarizme sagleda celovito, uzimajući u obzir stepen njihove desemantizacije, njihovu difuziju u jeziku i socio-kulturni efekat koji takvi izrazi proizvode u komunikaciji. Imenica „cazzo“, koja je predmet ovoga rada, i frazeološki izrazi u kojima ona učestvuje, zahtevaju da prevodilac, s jedne strane, prepozna vrste upotrebe i konotativna značenja ove reči, da prema njima zauzme dosledan stav kada je reč o biranju prevodnih ekvivalenata i da rekurzivne vulgarizme - kada se oni pojave - prenosi na homogen način, čuvajući na taj način autorove stilske intencije i kolorit likova. Zbog saprisustva ovih činilaca, delikatan je zadatak da se za predmetni italijanski vulgarizam iznađu, od slučaja do slučaja, srpski ekvivalenti koji su slični po pitanju desemantizacije, difuzije i socio-kulturne prihvatljivosti. Ovaj zadatak zahteva dobro poznavanje jednog i drugog jezika, ali i određenu slobodu i kreativnost u oblikovanju teksta prevoda. Kako smo prikazali u ovom radu, u nekim slučajevima ovaj zadatak nije obavljen na zadovoljavajući način, ali upravo takva mesta predstavljaju priliku za lingvističko promišljanje i za pitanje o mestu vulgarizama u srpskoj lingvistici i leksikografiji, za pitanje da li je ovom segmentu jezika posvećena dovoljna pažnja stručnjaka. Naše konstatacije imaju prvenstveno cilj da ukažu na činjenicu da pred vulgarizmima prevodilac treba da zauzme distanciran i objektivan stav i da pažljivo sagleda funkcionalnu, pragmatičku i socio-kulturnu dimenziju vulgarnog izraza koji bi mogao biti ekvivalent italijanskog vulgarizma adaptirajući tekst u onim slučajevima kada ne postoje valjani prevodni ekvivalenti. 
ITALIJANSKI VULGARIZAM „CAZZO“ I NJEGOVO PREVOĐENJE NA SRPSKI JEZIK

IZVORI NA ITALIJANSKOM JEZIKU

Moča 2006: Moccia, F. (2006). Ho voglia di te. Feltrinelli. Milano.

Moča 2007: Moccia, F. (2007). Scusa ma ti chiamo amore. Feltrinelli. Milano.

Moča 2009: Moccia, F. (2009). Scusa ma ti voglio sposare. Rizzoli. Milano.

Moča 2013: Moccia, F. (2013). Quell'attimo di felicità. Mondadori. Milano.

\section{IZVORI NA SRPSKOM JEZIKU}

Moča 2008: Moča, F. Izvini, ali ti si moja ljubav. Okean. Beograd. Prevela: Biljana Janković.

Moča 2011: Moča, F. Izvini, ali hoćeš li da se udaš za mene? Čarobna knjiga. Beograd. Prevela: Biljana Janković.

Moča 2014: Moča, F. Taj trenutak sreće. Čarobna knjiga. Beograd. Prevela: Svetlana Novaković.

Moča 2015: Moča, F. Želim te. Čarobna knjiga. Beograd. Prevela: Biljana Janković.

\section{LITERATURA}

Ambrođo i Kazalenjo 2004: Ambrogio R. / Casalegno G. Scrostati gaggio. Torino: UTET.

Bogdanović 2003: Bogdanović, N. Budalina igračka (Prilozi za srpski erotski rečnik). Niš: Prosveta.

Bogdanović 1997: Bogdanović, N. I ja tebi (izbor iz psovačke frazeologije). Niš: Prosveta.

Kapuano 2007: Capuano, R. G. Turpia. Sociologia del turpiloquio e della bestemmia. Milano: Costa\&Nolan.

Kazalenjo i Gofi 2005: Casalegno G. / Goffi G. Brutti, fessi e cattivi. Torino: UTET.

Deanović-Jernej 1998: Deanović, M/Jernej, J. Talijansko-hrvatski rječnik. Trinaesto, izmijenjeno izdanje. Školska knjiga, Zagreb

Golubović 2008: Golubović, B. Komunikativni frazeologizmi u srpskom žargonu. Razvojni procesi i inovacije u srpskom jeziku. Naučni sastanak slavista u Vukove dane 38/1. Beograd: MSC/Filološki fakultet.

Karadžić 1818: Karadžić, V. S. Srpski rječnik. Beč.

Klajn 2011: Klajn, I. Italijansko-srpski rečnik. Peto izdanje. Beograd: Alexandria.

Malobabić 2000: Malobabić, Ž. Psovka u jezicima danas i u istoriji. Međunarodni naučni skup. Filozofski fakultet, Novi Sad, Odsek za srpski jezik i lingvistiku, 27-28. oktobar. 
Nežmah 1997: Nežmah, B. Kletvice in psovke. Ljubljana: Nova revija.

Ristić 1994: Ристић, С. Опсцене речи у Речнику САНУ. У Опсцена лексика. Ниш : Просвета, 18-28.

Ristić 2010: Ristić, S. Diskurs psovki u srpskom jeziku. U: Vasić Vera (ur.), Diskurs i diskursi. Zbornik u čast Svenke Savić. Novi Sad: Filozofski fakultet, 193-212.

RMS 1967-1976: Rečnik srpskohrvatskog književnog jezika. Novi Sad: Matica srpska.

Ronkoroni 2017: Roncoroni F. Ingiurie \& insulti. Milano: Mondadori Educational,.

RSANU 1959: Rečnik srpskohrvatskog književnog i narodnog jezika. Beograd: Srpska akademija nauka i umetnosti.

Savić i Mitro 1998: Savić, S. / Mitro, V. Psovke u srpskom jeziku. Serija: Razgovorni srpski jezik, knjiga 3. Novi Sad.

Savić 1995: Savić, S. Istraživanje savremenog gradskog kompleksa: diskursne osobine psovki. Naučni sastanak slavista u Vukove dane 23/2. Beograd: MSC/Filološki fakultet, 161-176.

Savić 1996: Savić, S. Istraživanje savremenog gradskog kompleksa: upotreba psovki u konverzaciji. Naučni sastanak slavista u Vukove dane 24/1. Beograd: MSC/Filološki fakultet.

Šerbo 1991: Scerbo, E. Il nome della cosa. Oscar Milano: Mondadori..

Šipka 1999: Шипка, Д. Опсцене речи у српском језику. Београд/Нови Сад: ЦПЛ, Прометеј.

Vasić 2010: Vasić, V. Diskurs i diskursi. Zbornik u čast Svenke Savić. Novi Sad: Filozofski fakultet, 337-354.

Tartamela 2006: Tartamella V. Parolacce. Perché le diciamo, che cosa significano, quali effetti hanno. Milano: BUR Saggi.

Valić Nedeljković 1995/96: Valić Nedeljković, D. Psovke u sredstvima masovnog komuniciranja, u: Branislav Stojković (ur.) Kultura. Beograd. 


\title{
Saša Moderc \\ Maurizio Barbi
}

\section{ITALIAN VULGAR EXPRESSION „CAZZO“ AND ITS TRANSLATION INTO SERBIAN}

\begin{abstract}
Summary
Translating vulgar expressions from one language to another poses a series of problems, originated partly by the fact that they are sometimes ignored in bilingual dictionaries, as is the case with the Italian word "cazzo" in Klajn's Italian-Serbian and Deanović-Jernej's Italian-Croatian dictionaries. Limited information that can be retrieved from these sources gives hardly any data about thedesemantization, frequency and acceptability of some vulgar expressions today'sitalian society.Starting, roughly, from the Eighties, Italian literature has registered an increased presence of vulgar expressions; this phenomenon followed after the spread of a more liberal linguistic attitude. Vulgar expressions were originally (but not exclusively) part of youth speech and colloquial Italian; thanks to mass media, political engagement and protests of young people in the Seventies and, lately, thanks to Internet, these words became more visible and, consequently, entered Italian literature. Authors like Eco, Magris or Vassali refused to take part in this linguistic trend, but in others, like Benni, Ammaniti, Volo etc. it is possible to register a conspicuous number of vulgar expressions that earlier writers used to avoid (we refer to authors like Calvino, Pavese, Vittorini, Buzzati). On the other hand, Serbian lexical equivalent of "cazzo", "kurac", hasn't undergone a similar process of desemantisation and diffusion in language and keeps most of its linguistic unacceptability and vulgarity. The problem that had to face Serbian translators of four novels written by Federico Moccia was finding the lexical equivalent for the connotative (and dominant) values of Italian word "cazzo", thathas more than two hundred occurrences in analyzed Moccia's novels. The word "cazzo" was registered mainly as an independent exclamation (with nearly a dozen equivalents in Serbian) and as an emphatic element after interrogative pronouns and adverbs (chi, che, dove, quando, perché etc.).It is also used as part of negations ("non contare un cazzo", "col cazzo"), as an attribute ("quel cazzo di cellulare") and in idiomatic expressions ("non fregarne un cazzo a qcn.", "stare sul cazzo a qcn.", "rompere il cazzo a qcn.", "testa di cazzo", "(fare qcs.) a cazzo").Serbian translators in some cases opted for a
\end{abstract}


Saša Moderc, Maurizio Barbi

literal translation, producing a text with more vulgar traits than the original: this fact proofs that translating vulgar expressions requires linguistic competence and awareness of the sociolinguistic impact and acceptability of vulgar expressions in both languages.

Key words: Federico Moccia, cazzo, kurac, vulgar expressions, translation, Serbian language, Italian language, recursivity, socio-linguistic dimension. 